\section{UK to stay in Europe}

Britain's Medical Research Council (MRC) has advised the Advisory Board for the Research Councils that the United Kingdom should adopt a whole-hearted commitment to the European Molecular Biology Laboratory (EMBL) in Heidelberg, West Germany. The news has come as a relief to EMBL, which has lived under the threat of a possible withdrawal of UK support ever since the Advisory Board for the Research Councils asked MRC to consider the benefits of UK participation in EMBL just over a year ago. The board will consider MRC's advice on 31 January.

The MRC view is based on a detailed assessment of the benefits and costs of UK participation in EMBL and the scientific merits and cost effectiveness of the research carried out there. The assessment, carried out by a group of five senior British scientists, concluded that the case for remaining in EMBL is strong on scientific grounds alone and remains strong even when costs are taken into account.

The group is not persuaded that the $£ 1.2$ million contributed by MRC to EMBL in 1983 ( $£ 1.5$ million is due this year) would have purchased "an equivalent amount of work of equal quality" within the United Kingdom but does believe that EMBL's value for money should be increased.

The group recommends a more effective system of peer review and cost accounting for each of EMBL's scientific programmes but acknowledges that Professor Lennart Philipson has moved in the right direction since becoming director general of EMBL in 1982. It strongly approves of his new system of financial management of programme budgets, hopes and anticipates that costings will be linked to scientific reviews of the programmes but remains doubtful that the procedures for scientific review are adequate.

The problem, the group claims, is that the Scientific Advisory Committee of EMBL, which is charged with advising the laboratory council on EMBL's scientific programme, is in danger of being "seen as a creature of the director general" rather than offering independent advice to which the director general should be free to reply. Again, it welcomes Professor Philipson's moves to avoid such criticism but wants them further discussed and extended.

To judge the cost-effectiveness of EMBL, the MRC group chose to compare it with the MRC Laboratory of Molecular Biology (LMB) in Cambridge. The figures, summarized in the accompanying table, confirm suspicions that staff costs in Heidelberg are double those in Cambridge. The group considers that differential to be inevitable, given the salaries at comparable laboratories, notably the European Organization for Nuclear Research (CERN) near Geneva, and the allowances expected by expatriates on short-term contracts. It also considers the greater recurrent costs at EMBL to be justified and points out that expenditure on consumables is equivalent in the two laboratories. The only way to cut costs, the group implies, would be to reduce staff - if stringent peer review revealed weaknesses.

The MRC group's view of the current scientific programmes at EMBL is that, like the curate's egg, it is good in parts. The cell biology programme excels and the outstation programmes at Institut LaueLangevin, Grenoble and the DESY synchrotron in Hamburg are good. On the other hand, the recent investment in a differentiation programme is speculative and that on molecular structures is too large. Both instrumentation programmes are thought to be somewhat contrived to meet the original aim of EMBL to develop unique and expensive technology that few national laboratories would touch.

Costs at EMBL compared with LMB

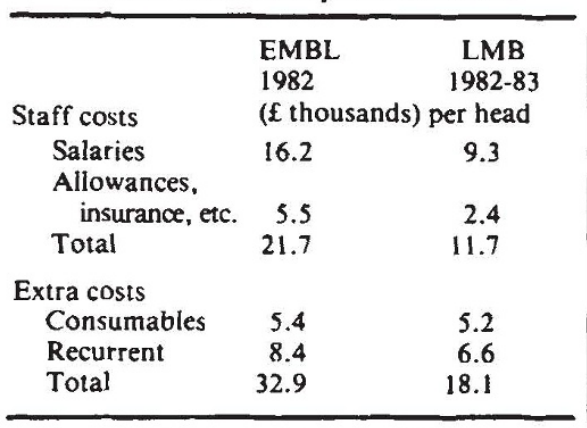

Total EMBL expenditure for 1982 was $£ 9.4$ million of which 54.7 per cent was spent on the cost of 232 "man-years" of staff. Total L.MB expenditure for $1982-83$ was $£ 4.6$ million of which $\mathbf{4 7 . 3}$ per cent was spent on the cost of 186 "fuil-time equivalents" of staff.

Overall the MRC group argues that the benefits the United Kingdom receives from participating in EMBL outweigh those of withdrawing, even if there would be a short-term financial gain in doing so. Professor Philipson, who is generally pleased with the report, questions whether there would be even a short-term gain, once proper account was taken of the cost to the United Kingdom of redeploying many of the British nationals (about 20 per cent of the total) employed at EMBL. Mr D. Noble, MRC under-secretary, claims that the group's calculations did include that possibility.

Noble also said that MRC would be surprised if the Advisory Board for the Research Councils did not accept its recommendation to continue UK participation in EMBL. He hoped that the board would now see fit to advise the UK Government that its science budget should be adjusted to protect the MRC budget against losses at the expense of increased contributions to EMBL due to changes in the UK economy.

Peter Newmark
UK public health Pathogens for suburbia?

Two laboratories at the UK Centre for Applied Microbiology and Research (CAMR) at Porton Down, in Wiltshire, England, may be closed in order to reduce costs. The two laboratories, the Special Pathogens Reference Laboratory and the Environmental Microbiology and Safety Reference Laboratory, carry out a varied programme of research in viral diagnosis, the production of vaccines and viral safety testing.

The proposal to close the laboratories is one of the options to be considered at a meeting of the Public Health Laboratory Service Board, on 26 January. Routine diagnostic work and possibly some safety work may be transferred from Porton to the new Central Public Health Laboratory building under construction at Colindale, in North London. Dr C. Gordon Smith, chairman of the Public Health Laboratory Service Board, says that a number of proposals will be discussed but stresses that none has yet been examined in detail and that no decisions have been made.

The news that diagnostic work might be moved to London nevertheless made front page news in the The Standard of London, under the banner headline GERM LAB PLAN FOR LONDON. Laboratory diagnosis of viral diseases, including Lassa fever and smallpox, has in fact been carried out at the existing Public Health Laboratory building at Colindale, which includes a high containment laboratory, since 1946. A statement issued by the Public Health Laboratory Service and the Department of Health and Social Security to calm the fears of Colindale residents says that "research involving highly dangerous organisms" will not be transferred to Colindale.

Among the staff of the threatened laboratories at Porton there is concern of a different kind. The work carried out there includes research on Ebola virus, Lassa fever and Marburg disease, and is aimed at reducing reliance on animals in diagnosis and producing vaccines. Botulinum toxoids and anthrax and experimental whooping cough vaccines are also manufactured.

Porton staff hold that closure of the laboratories or partial transfer of some of the work to Colindale cannot be justified financially, and point out that experimental work is probably better carried out in a remote area.

It is far from certain whether the Health and Safety Executive would allow some of the work to be transferred to London. The staff at Porton say that they represent a national asset that becomes invaluable in an emergency and may spawn products of commercial value and complain that CAMR seems likely to be hit harder than other Public Health Service laboratories.

Tim Beardsley 